\title{
Process optimization, design and analysis of horizontal Indexing cage fixture
}

\author{
Vishal Kumar ${ }^{1}$, Prof. Dr. S.G. Taji ${ }^{2}$ \\ ${ }^{I}$ (Mechanical Engineering, S.R.C.O.E. Lonikand/Pune University, India) \\ ${ }_{2}^{2}$ (H.O.D. of Mechanical Engineering, Govt. Polytechnic Ahmednagar, India)
}

\begin{abstract}
Project gives feasible solution to move and rotary indexing the component with full proofing fixturing for special purpose operations like drilling, Tapping, deburring, washing, drying involve in manufacturing and assembly. Rotary indexing type structure is made for handling the cylinder head inside the cleaning machine use for making fully ready component before assembly operation. System is useful to save time manpower and deliver perfect cleaned and dry component system involved all the mechanical components along with the sensors used to restrict the rotating operations, stop and go operations etc. Mechanical structure and possible loading conditions are studied and calculated to validate the bending, deformation and effect of external Excitation by operating tools while it takes indexing at different angle. Structure will rotate 360 degree with multiple stoppages and inside the structure cylinder block will be fixed automatically, stress values need to be calculated on multiple stoppages/indexing angles.
\end{abstract}

Keywords: Rotary indexing, Roller Wheel, Fixture, Strain, Stress, Vibration, Frequency

\section{Introduction}

Design of automated Rotary indexing Type Fixture For crank case is taken from the special purpose machine in which component crank case) is to be machined, cleaned ,dry, and proceed towards assembly section in continuous production line of Automobile company The arrangement of said project will be process wise well defined sequence and operation for the decided cycle time where the rotary Fixture along with component will be get stoppage at every angular position with the used sensors.Operation cycle will be run through PLC Programme.

\subsection{Problem Identification}

Rotation of crank case is not possible manually; in automated drilling and other operations component need to be rotate indexing mode so that robotic drill can be face the drilling surface with precision. Rotary cage is to be made to give feasible solution .deformation may occur while rotation stress may be increase at multiple angles as the load is coming directly on cage.

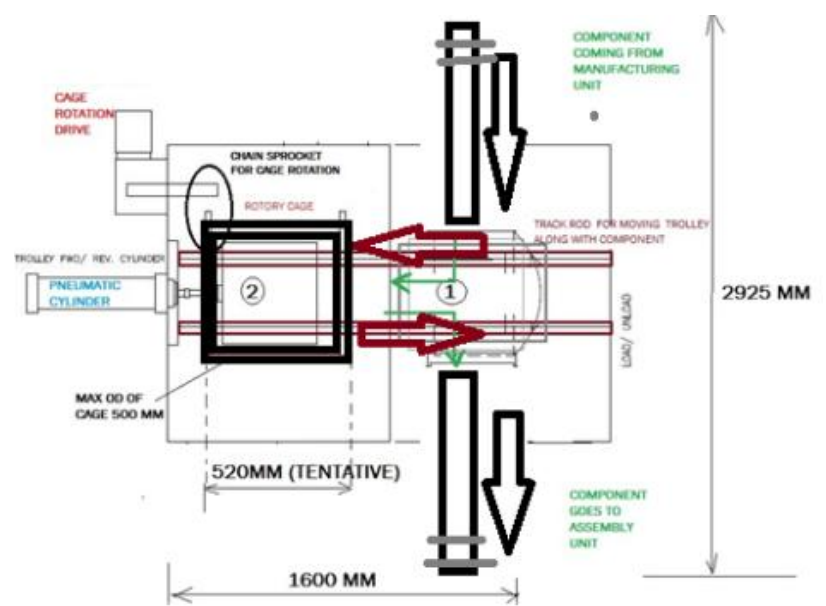

Fig. 1.1 Layout shows need of indexing

\subsection{Present Theories and Practices}

Without rotating component it can be operated by keeping operating face open toward tool it can be operated with only single process multiple processes can't be handle simultaneously, since ,face wise operation can be changed. After operating with tools component need to be clean before reaching to assembly section again another station component is transfers by moving fixture, here manual handling and manual air 
blow for cleaning ,cavities, holes, oil, coolant, dirt etc. It takes more time to complete all these processes, It will have been good if rotary indexing is provided in a single station with common fixturing with allowing face indexing only tools will change on same place and component will take rotation.

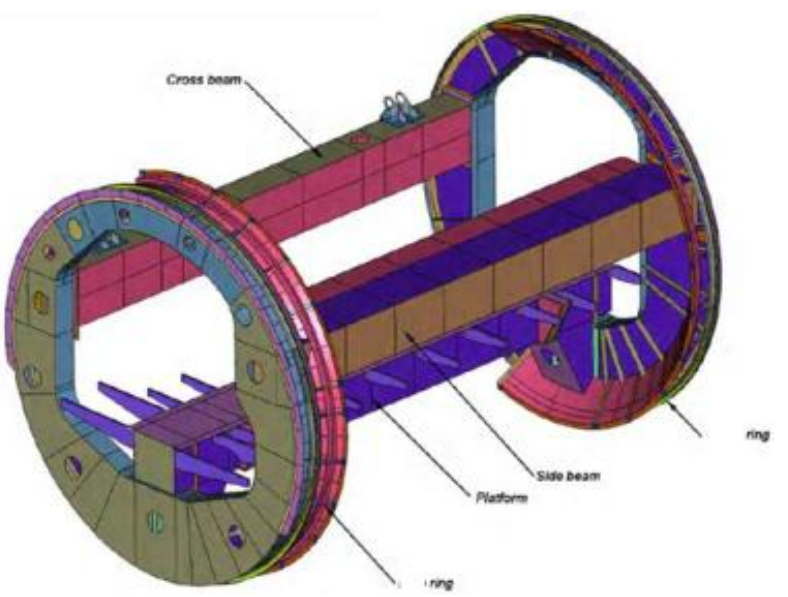

Fig. 1.2 Design of Existing Cage

\subsection{Design Input}

1.3.1 Total set of Fixtures Trolley required to be mounted - 1Nos

1.3.2 Total Weight Of components: $300 \mathrm{~kg}$

1.3.3 Maximum Available Area: $2 \mathrm{~m} \times 3 \mathrm{~m}$.

1.3.4 Loading Height: $1000 \mathrm{~mm}$ from ground.

1.3.5 Degree of rotation for cage -360 degree.

1.3.6 Material for manufacturing - AISI 304.

1.3.7 3D model of crank case.

1.3.8 Trolley Fixture model already available

1.3.9 Indexing structure to be designed for this assembly.
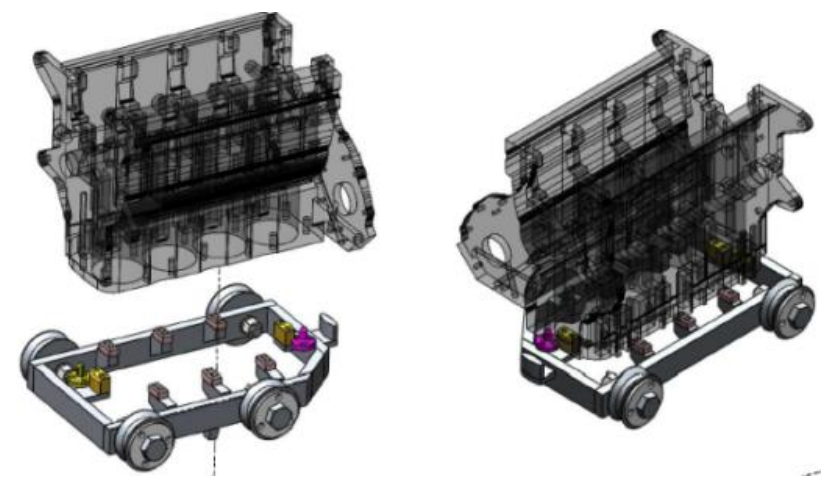

Fig 1.3 Trolley

\section{Literature Review}

Taufif Bin Zakaria and Wang and Rong (2008) formulated a fixture design problem in hierarchical design structure and presented the case based reasoning method to provide a computer aided fixture design solution. Perremans (1996) developed an expert system for automatic fixture design [1].

Thomapson and Ghadhi (1986) Worked on Fixtures which are important in both traditional manufacturing and modern flexible manufacturing system (FMS), which directly affect machining quality, productivity and cost of products. The time spent on designing and fabrication fixtures significantly contributes to the production cycle in improving current product and developing new products [2].

Gandhi M.V. and B. S. Thompson(1986), "Automated design of Modular fixture for Flexible manufacturing systems. Gandhi M.V. model the locating boundary conditions (i.e., the locators at their interface with the workpiece) as multiple springs in parallel that support friction loads and that the locating boundary conditions act over an area rather than acting as point contacts. Optimization of the locating points is achieved using a first 
order method. Inputs to the system are the work-piece geometry, the stiffness values for each point of location, and the machining values. The outputs of the system are a list of optimized locating points that minimize the work-piece deflection [3].

Nee \& Kumar (1991) also developed a rule-based automated fixture design. In addition to the functionality offered by Nnaji et al. Nee \& Kumar performed a limited check on the displacement likely at each locating point as a result of the machining forces and also implemented a simple justification module that employed heuristic rules to determine whether a modular (comprised from a set of standard components) or dedicated (custom) fixture design should be generated [4].

Shoji Naguchi, Satoshi Nakayama, (2009)et.al., "Static stress analysis of link plate of a roller chain using finite element method \& perform an optimization to select locating positions that minimize work-piece deflection during machining [5].

\section{Material Property}

Table 3.1

\begin{tabular}{|c|c|c|c|c|}
\hline Grade & $\begin{array}{c}\text { Design strength } \\
(\mathrm{N} / \mathrm{mm} 2)\end{array}$ & $\begin{array}{c}\text { Ultimate tensile strength } \\
(\mathrm{N} / \mathrm{mm} 2)\end{array}$ & $\begin{array}{c}\text { Young's Modulus } \\
(\mathrm{N} / \mathrm{mm} 2)\end{array}$ & Elongation (\%) \\
\hline \multicolumn{5}{|c|}{ Stainless steel } \\
\hline 304 & 210 & 520 & 200 & 25 \\
\hline 316 & 220 & 520 & 200 & 22 \\
\hline
\end{tabular}

\subsection{Design of fixture}

\section{Design Of Fixture And Calculation}

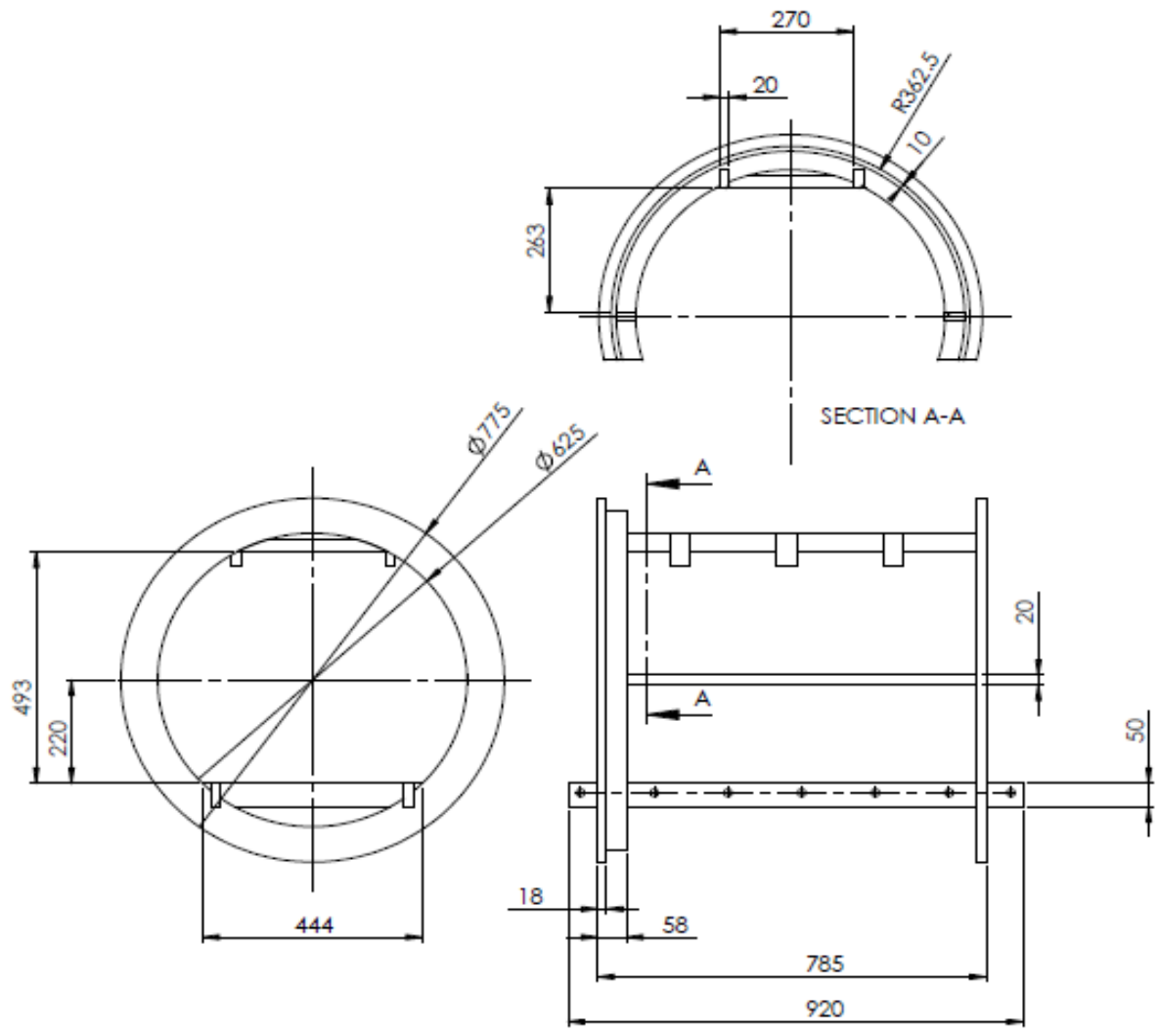

Fig 4.1 Cage design followed by taking component dimensions for fitment

Two locations are to be covered for drilling 8 numbers of holes. Component is slide $100 \mathrm{~mm}$ left side to make opening for tool entering. 


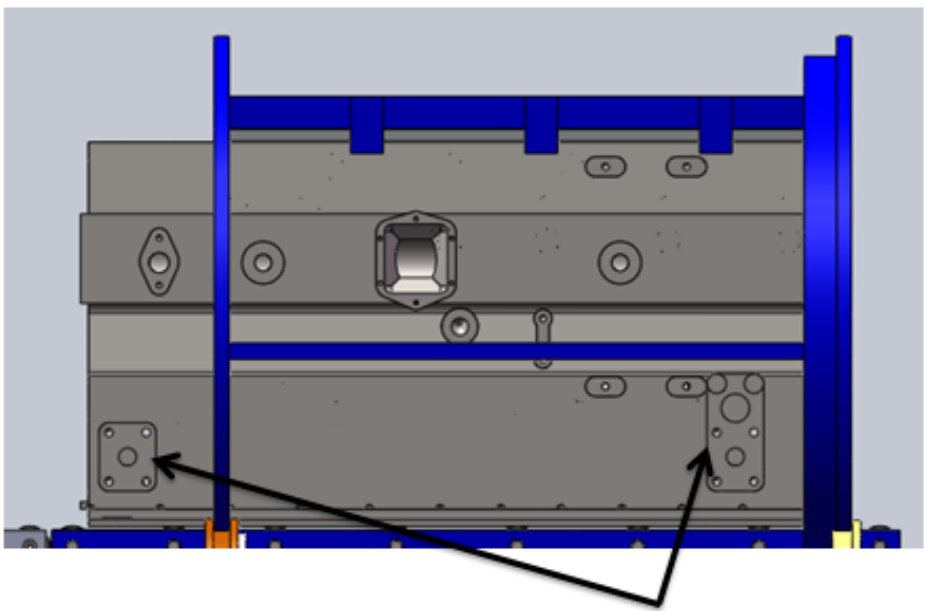

Fig 4.2 First Drilling Guide in Cage

Drilling face is to be opened to make machined here in previous design. Drilling face was covering by cage plat, now it's resolved by giving simple cut to the cage side.

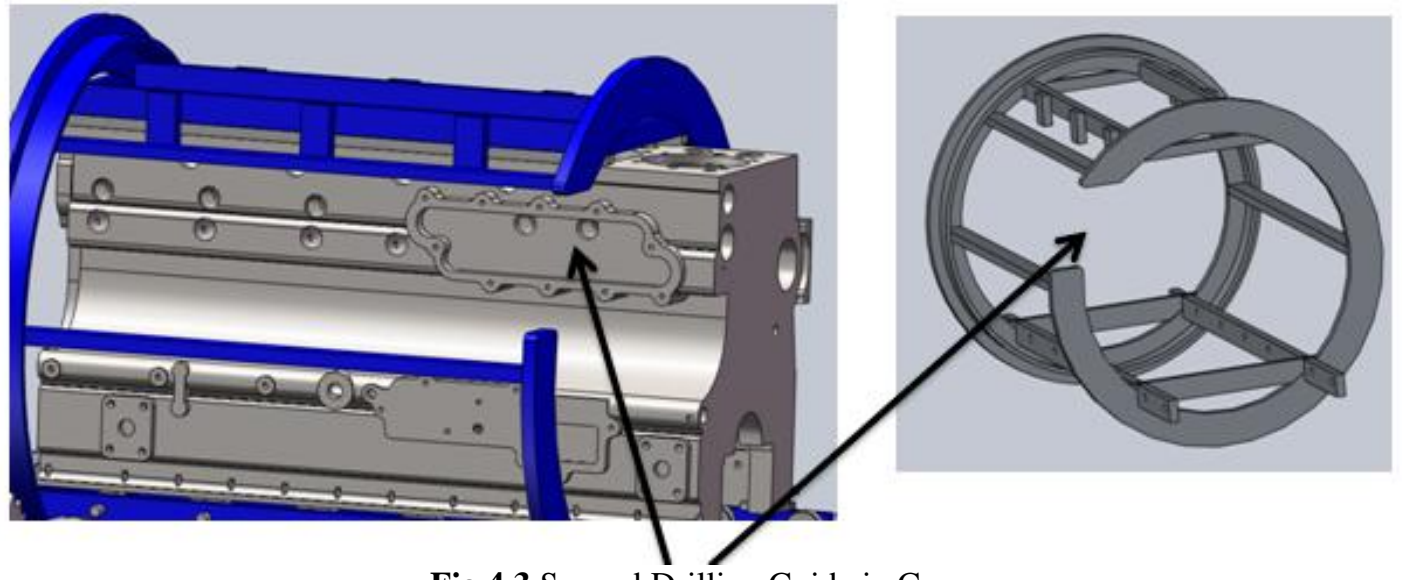

Fig 4.3 Second Drilling Guide in Cage

Multiple wheels will allow component to enter inside and unload by simple sliding by pushing and pulling operation by cylinder stroke. Drive unit made for the transmission of rotary motion into cage which is holding fixture cum component is made by considering the input parameters like speed and cycle time require for the process inside the machine.

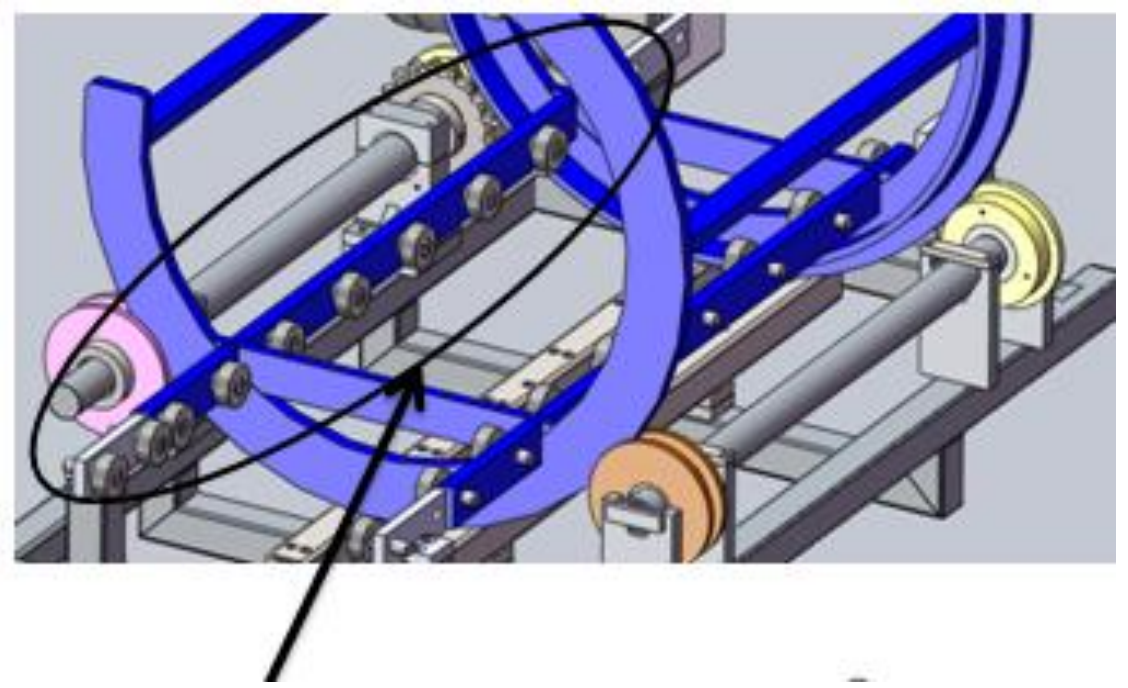

Fig 4.4 Bottom roller wheel for loading \& unloāing 


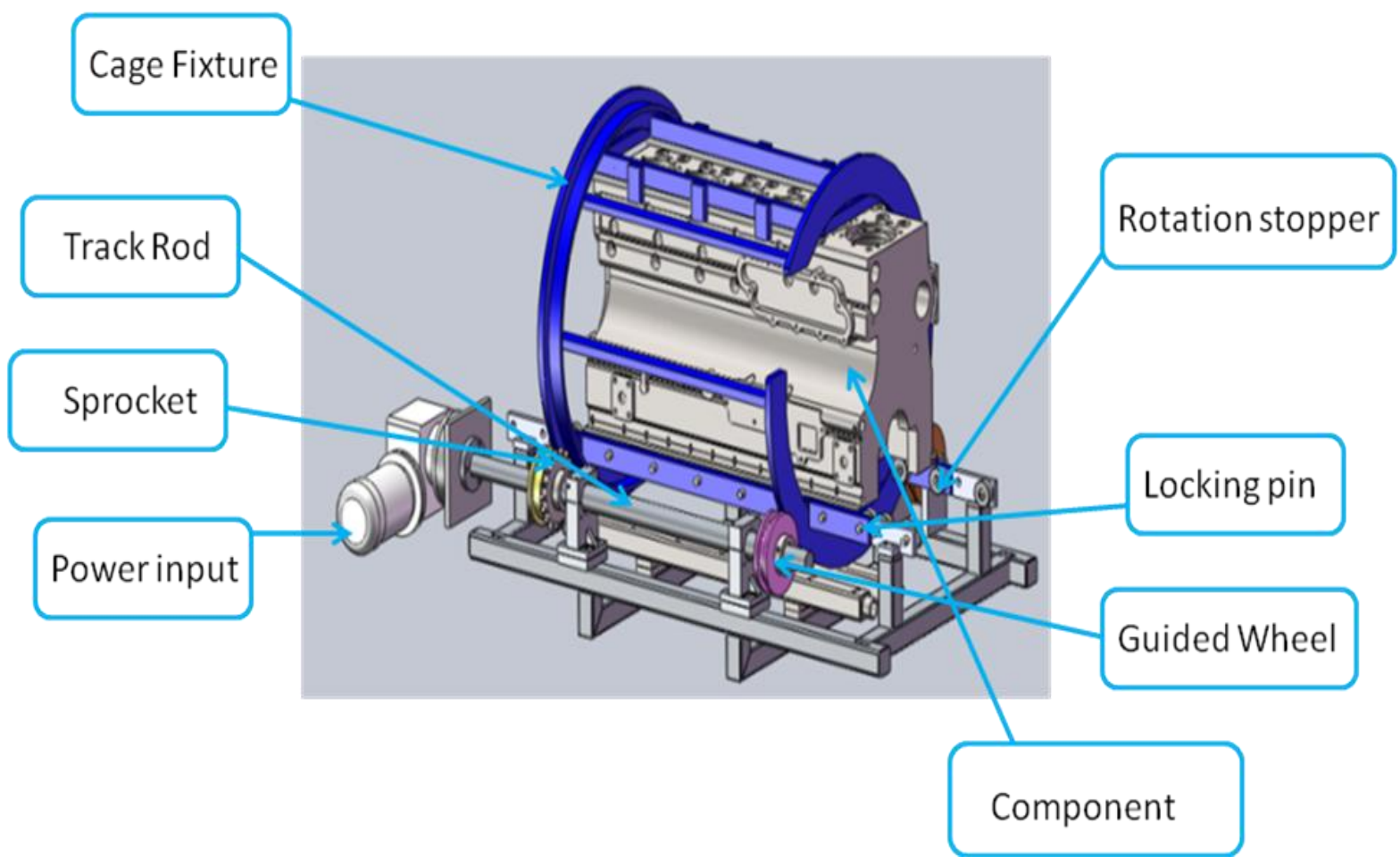

Fig 4.5 Assembly of driven unit with fixture and cylinder block

\subsection{Calculation for driven unit and track rod}

\section{Selection and final the parameters:}

Total CAGE weight $=110 \mathrm{~kg}$

Per component weight $=300 \mathrm{~kg}$

Maximum number of components at a time $=1$

For rolling applications, generally preferred value the coefficient of friction is 0.3 .

Total pulling weight $=$ Total cage weight $+($ Per component weight $\times$ Maximum no. of components at a time $)$

Hence,

1) Total pulling weight $=110+(300 \times 1)$

$$
=410 \mathrm{~kg} \text {. }
$$

Maximum Pull $=$ Total Pulling weight $\times$ Coefficient of Friction

$$
\begin{aligned}
& =410 \times 0.3 \\
& =123 \mathrm{~kg}
\end{aligned}
$$$$
=1230 \mathrm{~N}
$$

2) For PCD of Drive sprocket,

$$
\text { Consider } \mathrm{g}=10 \mathrm{~m} / \mathrm{s}^{2}
$$

$$
\text { Chain pitch }(\mathrm{P})=25.4 \mathrm{~mm}
$$

Number of teeth on sprockets $(\mathrm{z})=17$

$$
\text { Time to travel pitch }(\mathrm{t})=60 \mathrm{sec} \text {. }
$$

Pitch Circle Diameter of Drive Sprocket $=$ Pitch $(\mathrm{P}) / \sin (180 / \mathrm{z})(\pi / 180)$

Hence,

$$
\begin{aligned}
\text { PCD of Sprocket } & =25.4 / \sin (180 / 17)(\square / \mathbf{1 8 0}) \\
& =138.17 \mathrm{~mm} \\
& =0.138 \mathrm{~m}
\end{aligned}
$$

Since the driving sprocket is a ring bonded by chain of pitch $25.4 \mathrm{~mm}$

$$
\text { Ring dia } \mathrm{d}=725 \mathrm{~mm}
$$

$$
\text { Perimeter of ring }=2 \text { л } \mathrm{d}
$$

$$
=4553
$$

No. of pitch will be on ring $(z)=4553 / 25.4$

$$
=179.25
$$

Chain pitch $(\mathrm{P})=25.4 \mathrm{~mm}$

Number of teeth on drive sprockets $(\mathrm{z})=17$ 
Pitch between rotation components $\left(\mathrm{P}_{\mathrm{c}}\right)=4553 \mathrm{~mm}$ (considered after every rotation fresh cycle) Time to travel pitch $(\mathrm{t})=60 \mathrm{sec}$.

3) Centre distance between two Shafts $=(\mathrm{PCD}$ of Drive Sprocket $+\mathrm{PCD}$ of driven Ring $) / 2$

$$
\begin{aligned}
& =(1384+725) / 2 \\
& =431.5 \mathrm{~mm} \\
& =0.431 \mathrm{~m}
\end{aligned}
$$

4) Torque Calculation for Drive Unit

$$
\begin{aligned}
\text { Required torque }= & \text { Maximum pull } \times(\mathrm{PCD} \text { of Sprocket } / 2) \\
& =1230 \times(0.138 / 2) \\
& =85 \mathrm{Nm} \\
\text { Required RPM } & =\mathrm{P}_{\mathrm{c}} \times(\mathrm{t} / 60) \times(\mathrm{z} / \mathrm{P}) \\
& =4553 \times(60 / 60) \times(17 / 25.4) \\
& =10.544 \\
& =10.5 \mathrm{RPM}
\end{aligned}
$$

5) Final Result

Consider the service factor for the conveyor chain is 1.7

Hence,

Final output Torque, $(\mathrm{T})=$ required torque $\times$ Service factor

$$
\begin{aligned}
& =85 \times 1.7 \\
& =144.5 \mathrm{Nm}
\end{aligned}
$$

Final Output RPM, (n) $=10.5 \mathrm{rpm}$

Final Output HP $=(2 \times \pi \times n \times \mathrm{T}) / 45000$

$$
\begin{aligned}
& =(2 \times \pi \times 10.5 \times 144.5) / 45000 \\
& =0.212 \mathrm{HP}
\end{aligned}
$$

Track rod assessment

Total load $94 \mathrm{~kg}=940 \mathrm{~N}$ (74 kg of cylinder block $+19.6 \mathrm{~kg}$ of fixture trolley.)

Trolley loaded on two track rod by four wheels, point loading acting $235 \mathrm{~N}$ each point.
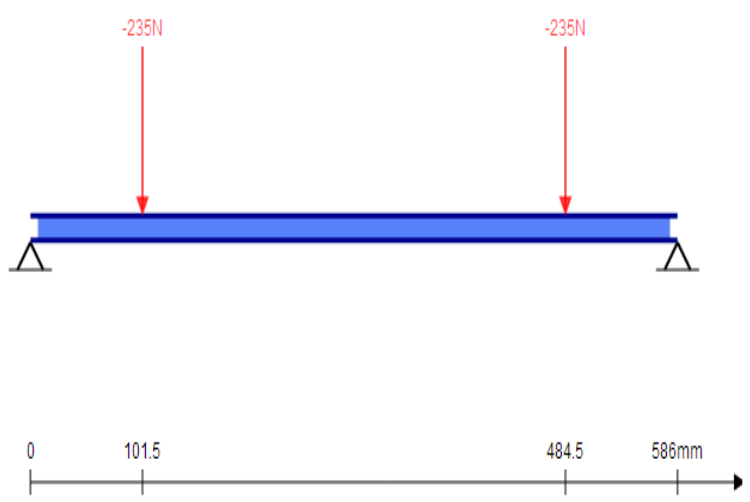

Vertical Reaction at the $0 \mathrm{~mm}$ support is: $235 \mathrm{~N}$

Vertical Reaction at the $586 \mathrm{~mm}$ support is: $235 \mathrm{~N}$

Fig 4.6 Loading on Rod (Simply supported) 

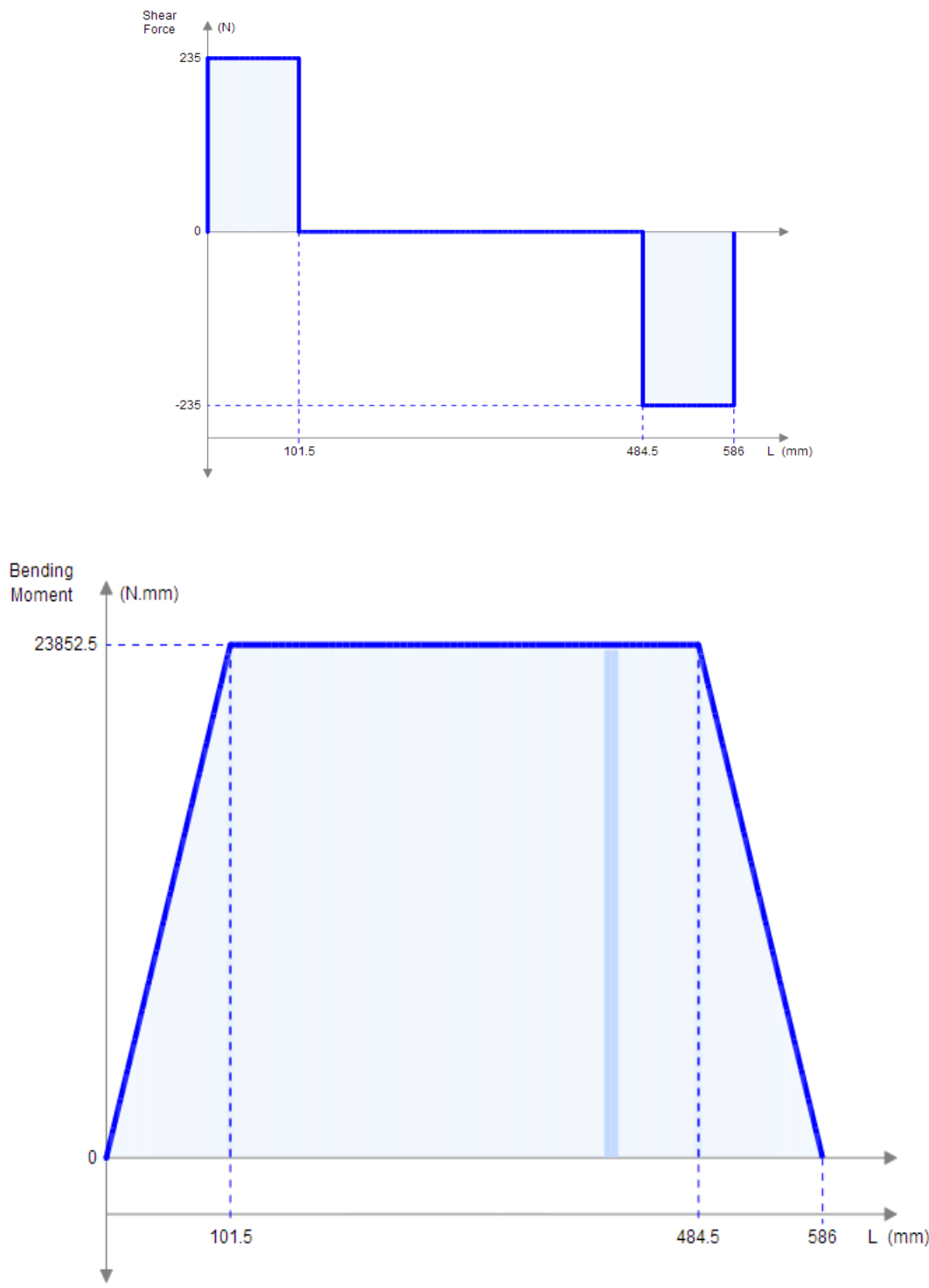

Fig 4.7 SFD \& BMD for Rod

\section{Finite Element Analysis}

The controls in this group set the basic size defaults for the initial mesh. Local controls (described later), can be used to override these values in specific regions of the model.

- These settings assume the "Use Advanced Size Function" is set to "Off".

- Relevance Canter: sets the midpoint of the "Relevance" slider control.

- Element Size: defines element size used for the entire model \& apply load $300 \mathrm{~kg}$ on the fixture using HW - 13

- Initial Size: Initial mesh size is based either on the entire assembly or on each individual part.

- Smoothing: Attempts to improve element quality by moving nodes. Number of smoothing iterations can be controlled (Low, Medium and High).

- Transition: Controls the rate at which adjacent elements will grow (Slow, Fast).

\subsection{Drum cage Fixture static analysis (Load 300kg)}




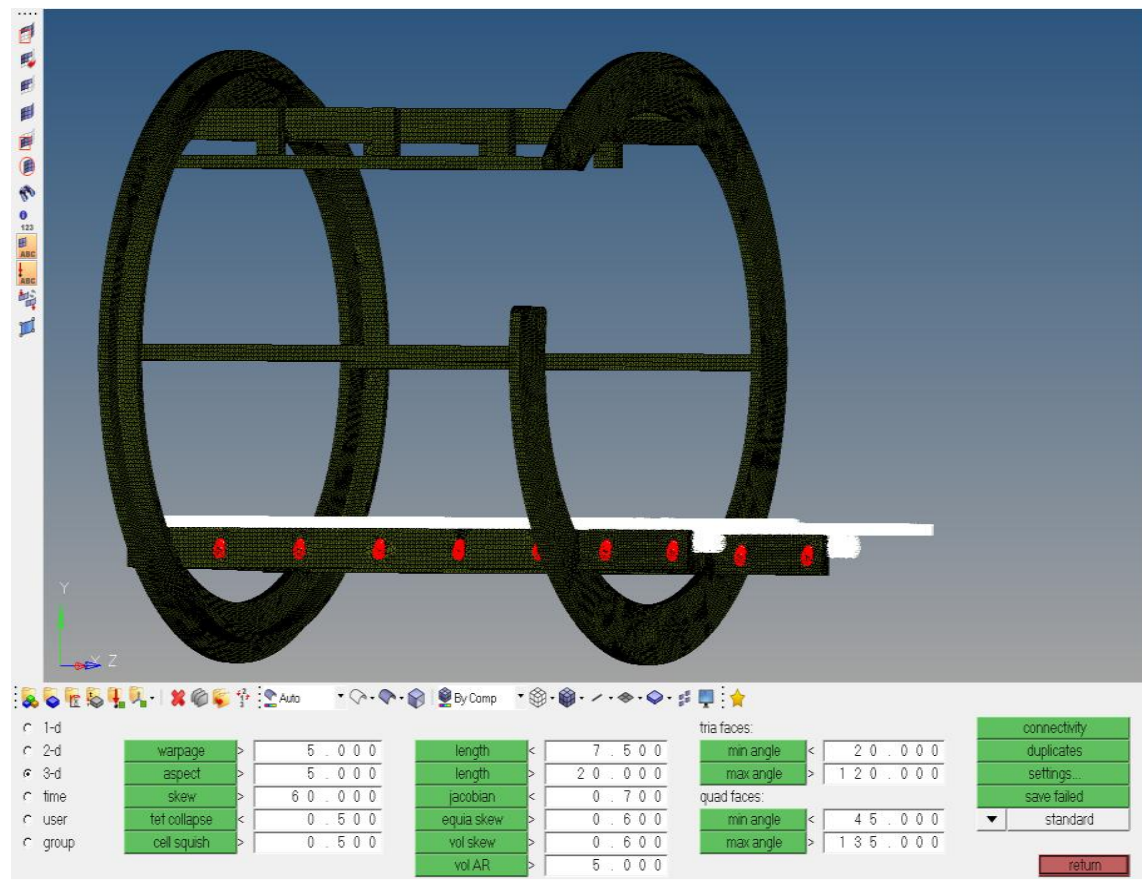

Fig 5.1.1 Model of Component with quality index

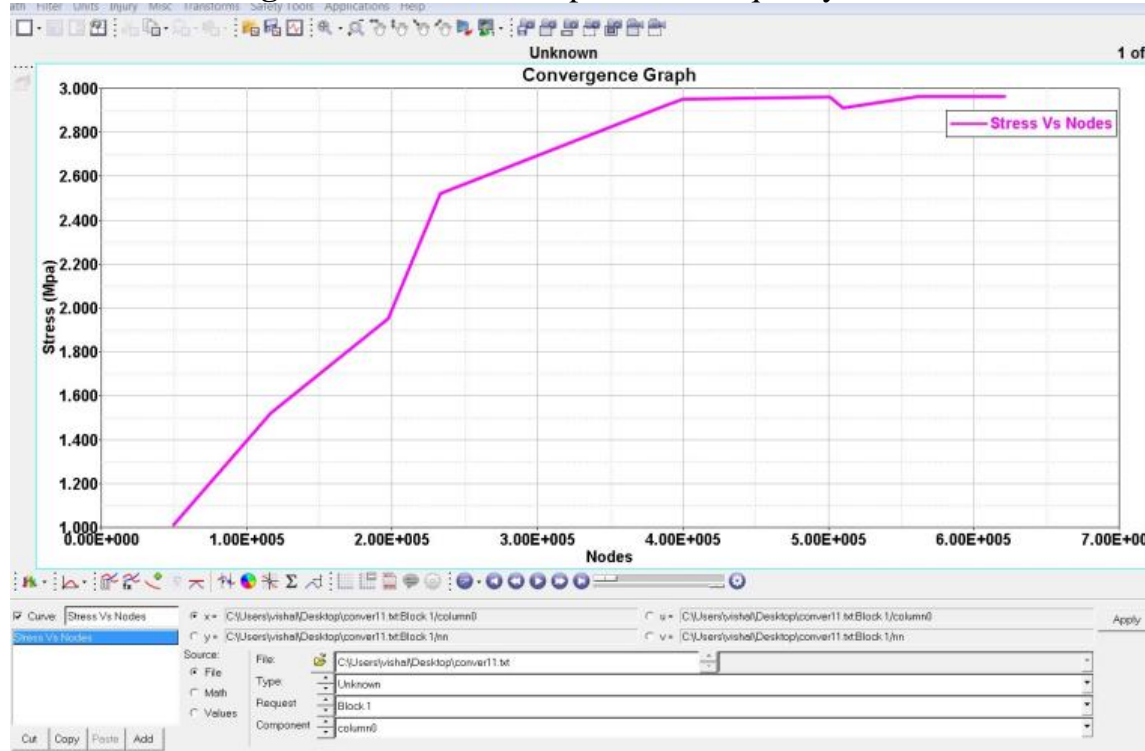

Fig 5.1.2 Convergence Criteria Graph 


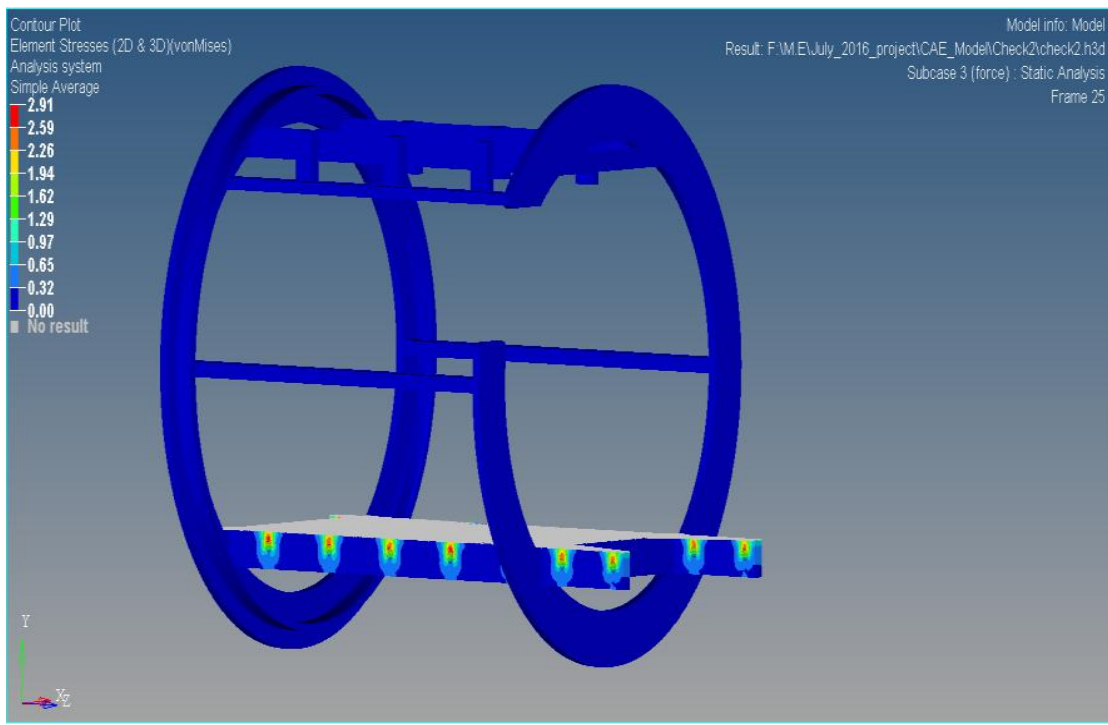

Fig 5.1.3 VonMises Stress of Fixture Structure for 90 Degree

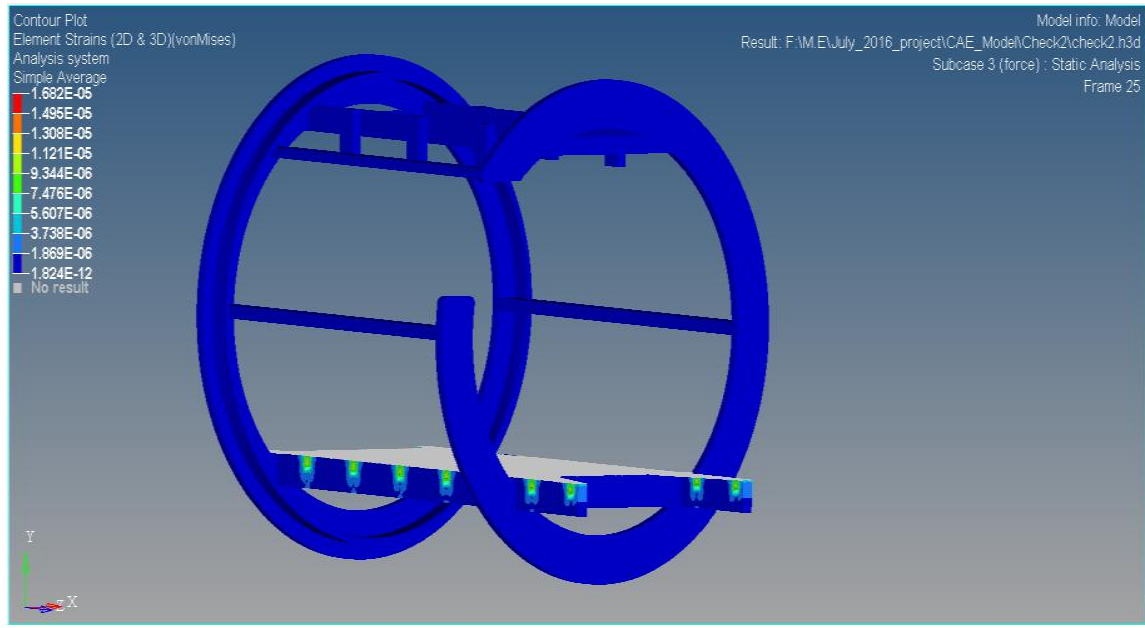

Fig 5.1.4 VonMises Strain of Fixture Structure for 90 Degree

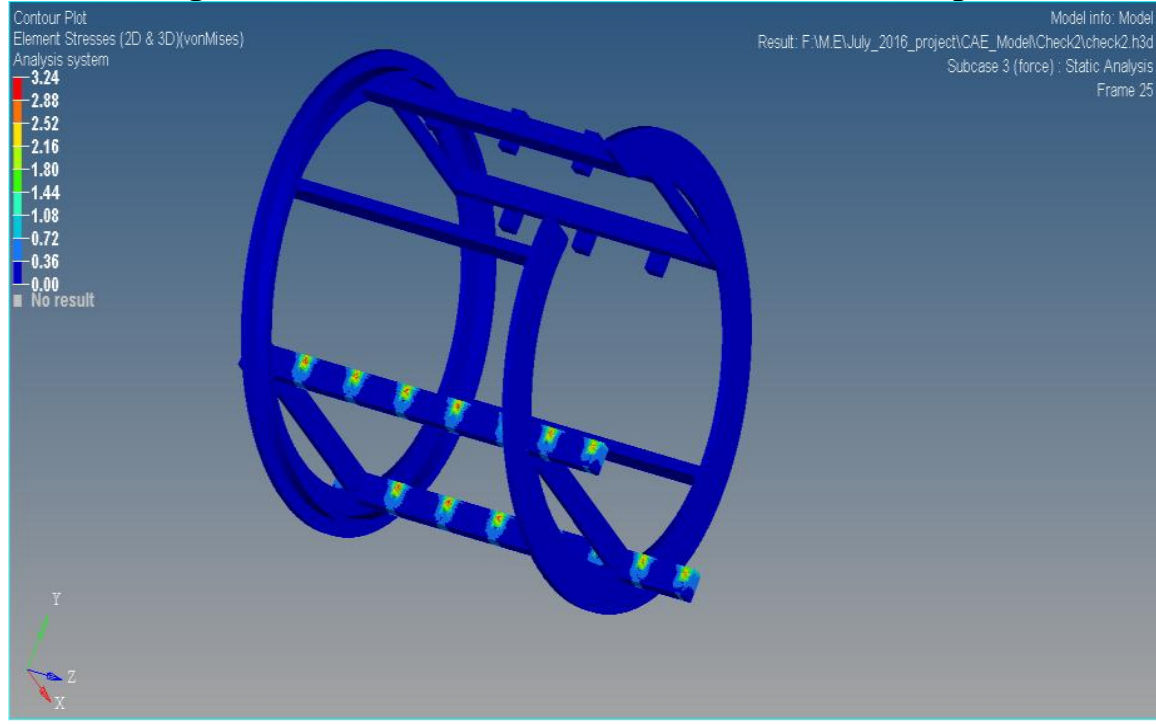

Fig 5.1.5 VonMises Stress of Fixture Structure for 45 Degree 


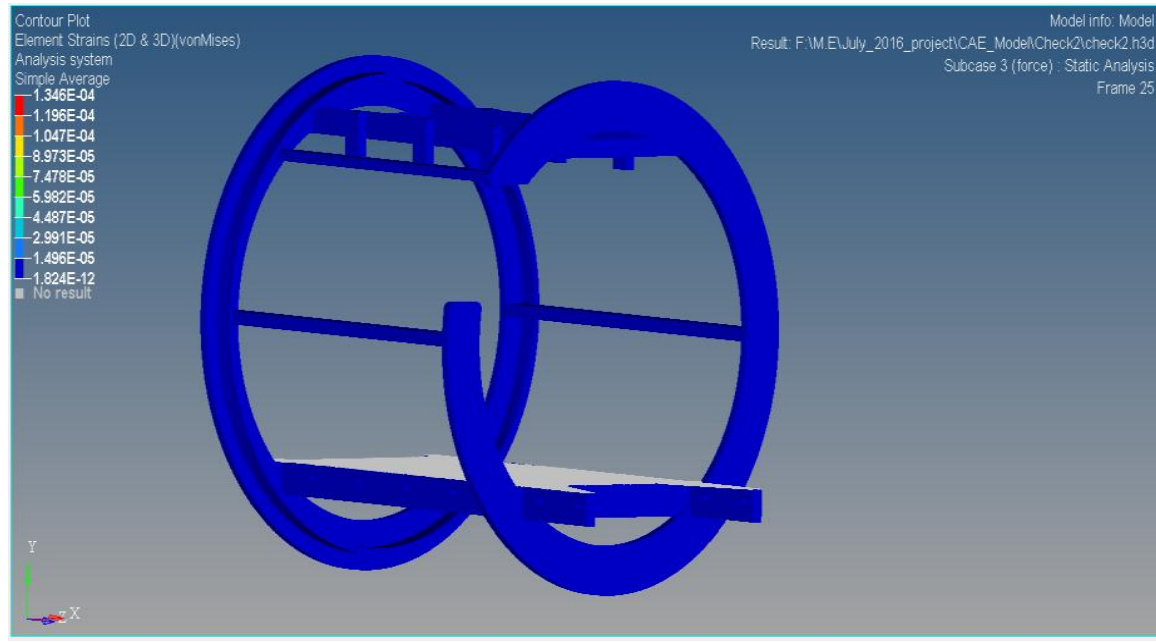

Fig 5.1.6 VonMises Strain of Fixture Structure for 45 Degree

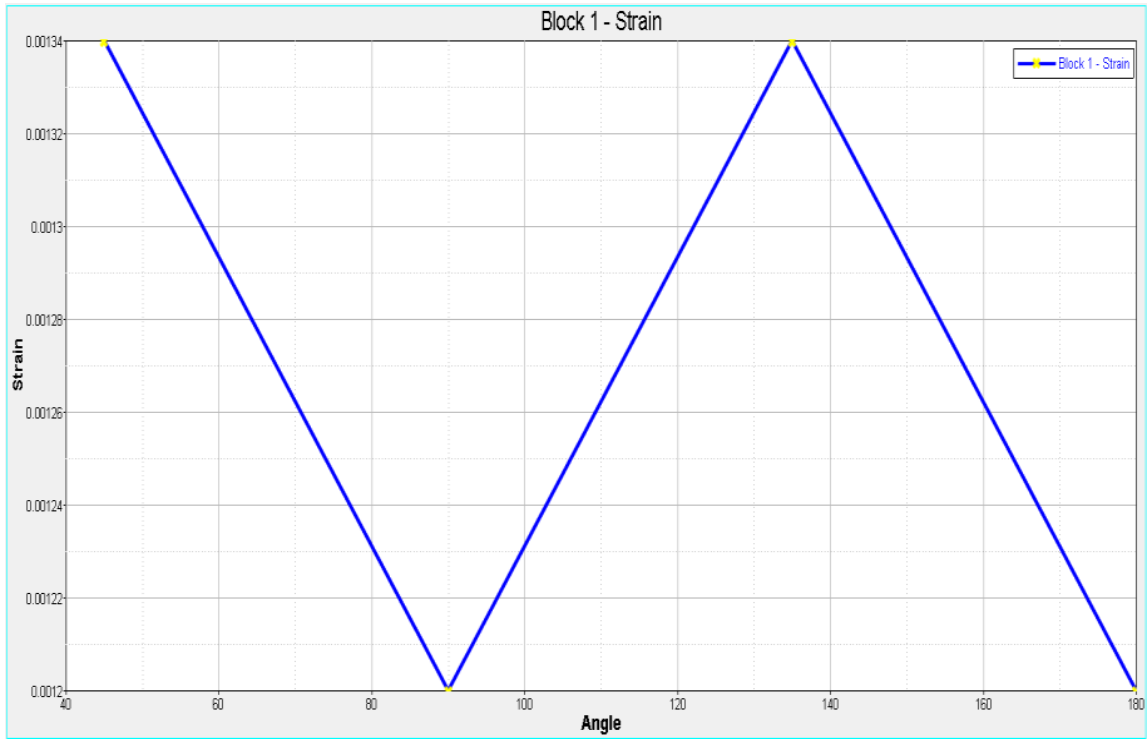

Fig 5.1.7 Strain at Different angle

\subsection{Structural Vibration Analysis}

The term vibration describes repetitive motion that can be measured and observed in a structure. Unwanted vibration can cause fatigue or degrade the performance of the structure. Therefore it is desirable to eliminate or reduce the effects of vibration. In other cases, vibration is unavoidable or even desirable. In this case, the goal may be to understand the effect on the structure, or to control or modify the vibration, or to isolate it from the structure and minimize structural response.

Vibration analysis is divided into sub-categories such as free vs. forced vibration, sinusoidal vs. random vibration, and linear vs. rotation-induced vibration.

\subsubsection{Modal Analysis}

Structures vibrate in special shapes called mode shapes when excited at their resonant frequencies. Under normal operating conditions, the structure will vibrate in a complex combination of all the mode shapes. By understanding the mode shapes, all the possible types of vibration can be predicted. Modal Analysis refers to measuring and predicting the mode shapes and frequencies of a structure. The mode shapes and resonant frequencies (the modal response) of a structure can be predicted using mathematical models known as Finite Element Models (FEM). These models use points that are connected by elements with the mathematical properties of the structure's materials. Boundary conditions define the method of fixing the structure to the ground and the force loads applied. After defining the model and boundary conditions, the FEM software computes the structure's mode shapes and resonant frequencies. This analytical model greatly aids in the design 
of a structure by predicting its vibration response before it is built. Finite Element Model of a Cage Fixture with force loads and boundary conditions.

\section{This analysis is carried out by Automotive Regulation JIS D 1601 Japanese Industrial Standard [18]}

After building the model, good practice requires verifying the FEM using experimental modal analysis. This identifies errors, particularity in the assumptions on the boundary conditions, to help improve the model for future designs. This analysis is also useful (FEM models) because it can identify the modal response of an existing structure to help solve a vibration problem.

Using software to visualize the mode shapes at several points on the structure and from natural frequency we find the response of frequency on structure using FRA (Frequency Response Analysis). Typically, the structure is divided into a node pattern with enough points to cover the entire structure, or at least the areas of interest. The size of the nodes depends of the accuracy needed. More nodes points require more measurements and take more time. One FRA measurement is made for every measurement location on the structure. The number of measurement points is determined by size and complexity of the structure and the highest resonant frequency of interest. High frequency resonances require a fine node to fully determine the mode shape. Each FRA identifies the resonant frequencies of the structure and the modal amplitudes of the measurement node point associated with the FRA. The mode shape is extracted by examining the vibration amplitudes of all the node points.

\subsubsection{Model Analysis \& Frequency Response Analysis by FEM}

Structural vibration is generally a result of the exciting force and dynamic properties of the structure. The same analogy can be used for any vibrating system. In modern engine development work all these different components - excitation, structure and vibration response - can be analyzed and taken into account at the design phase itself. Excitation forces with all possible firing orders can be compared and analyzed, structural properties like the stiffness of the Fixture can be optimized, and finally a dynamic simulation of the vibration response can be performed. Mathematically the general equation of motion: $M x_{-}(t)+C x_{-}(t)+K x(t)=f(t)$ where $M, C$ and $K$ are matrices of mass, damping and stiffness, $x(t)$ is the vector of displacement (response), and $f(t)$ is the vector of applied force (excitation).

Basically there are three important factors contributing to the vibration levels and behavior of a fixture.

- A rigid body motion of the Fixture on its flexible mounting: The Fixture is moving as a solid part, sometimes causing problems with connections.

- Deformation of the Fixture (global vibrations): When in resonance, this causes high stresses that might lead to failures.

- Local vibrations of a component: Vibrations of a component with respect to its mounting.

- To study the dynamic behavior of engine systems assembly by performing a modal analysis and to extract all modes below $200 \mathrm{~Hz}$, except the first six rigid body modes of the fixture on the mountings. Engine block and Engine Head are considered as rigid.

- The External excitation 4.5g is applied on fixture according to JIS Regulation and Performing a frequency response analysis for different firing order as given below:

CASE 1: $40-80 \mathrm{~Hz}$

CASE 2: $80-120 \mathrm{~Hz}$

CASE 3: $120-160 \mathrm{~Hz}$

CASE 4: $160-200 \mathrm{~Hz}$

For natural frequency analysis only one CARD_IMAGE is required 'EIGRL' with 10 Modes for creating load collector.

In frequency response analysis there are six Load required. All load case \& load steps are similar in X-axis and $\mathrm{Y}$-axis only change in axis where excitation is applied.

- Frequency

- Damping

- Excitation

- DLoad

- Natural frequency

- $\quad$ SPC(all DOF locked)

\subsection{Model Analysis (Natural Frequency)}

\section{Analysis Result}


The outputs of the solver is post-processed by Hyper View - 13.0. Firstly we extracted mode by freefree modal analysis and the first mode is coming on circular ring at $45.26 \mathrm{~Hz}$. Once the modal analysis is completed then frequency response analysis is performed.

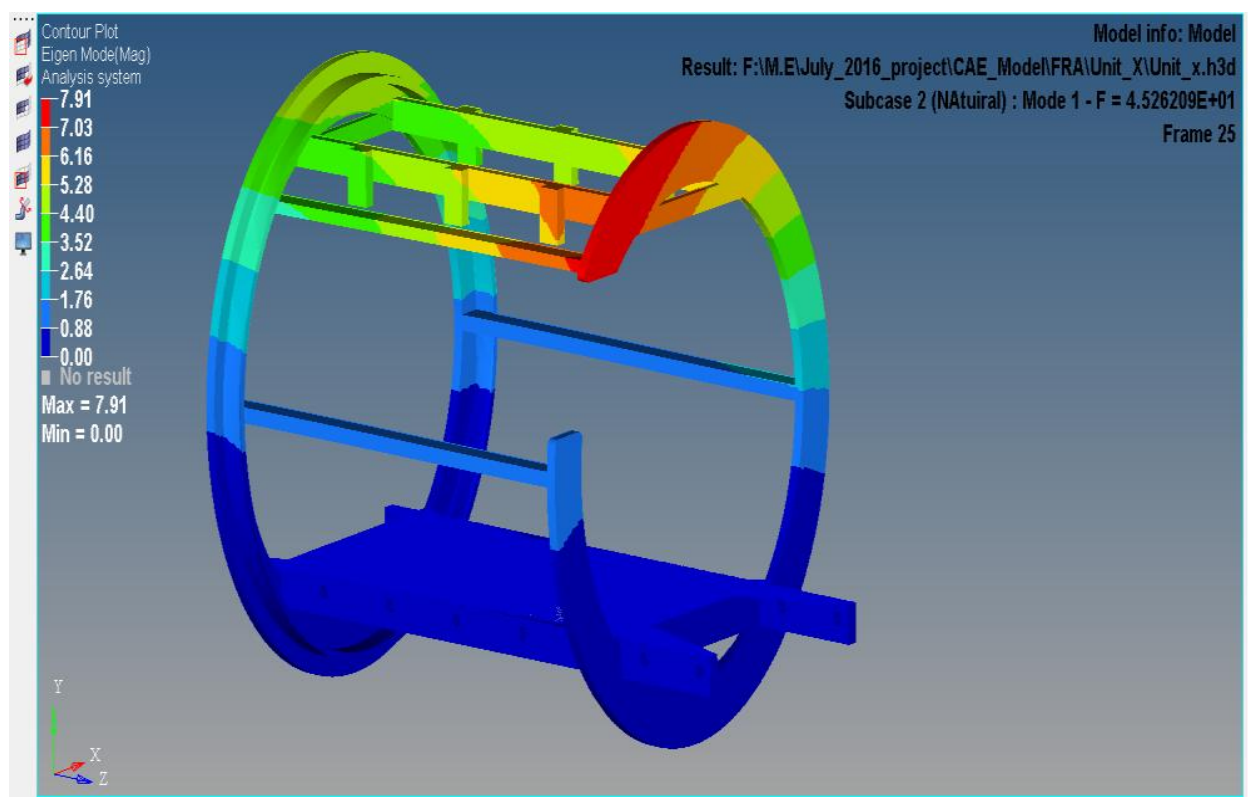

Fig 6.1.1 Mode 1

Table 6.1

\begin{tabular}{|c|c|}
\hline Number of MODES & Natural Frequency \\
\hline 1 & 45 \\
\hline 2 & 57 \\
\hline 3 & 107 \\
\hline 4 & 125 \\
\hline 5 & 137 \\
\hline 6 & 153 \\
\hline 7 & 172 \\
\hline 8 & 182 \\
\hline 9 & 189 \\
\hline 10 & 198 \\
\hline
\end{tabular}

\subsection{Frequency Response Analysis}

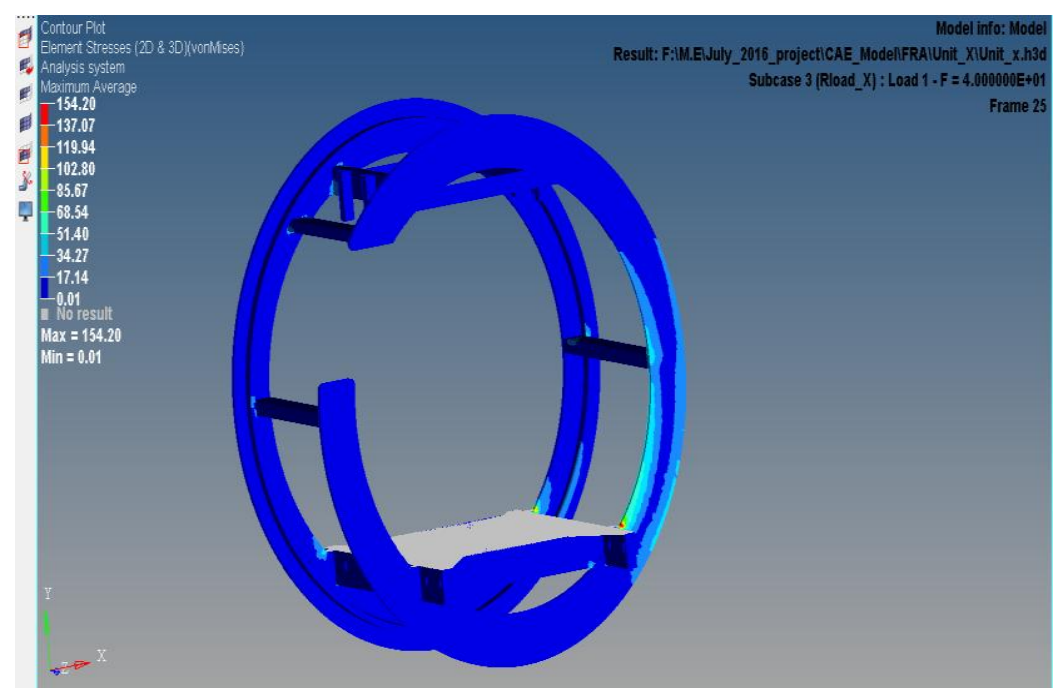

Fig 6.2.1 Stress plot for $40 \mathrm{~Hz}$ frequency 


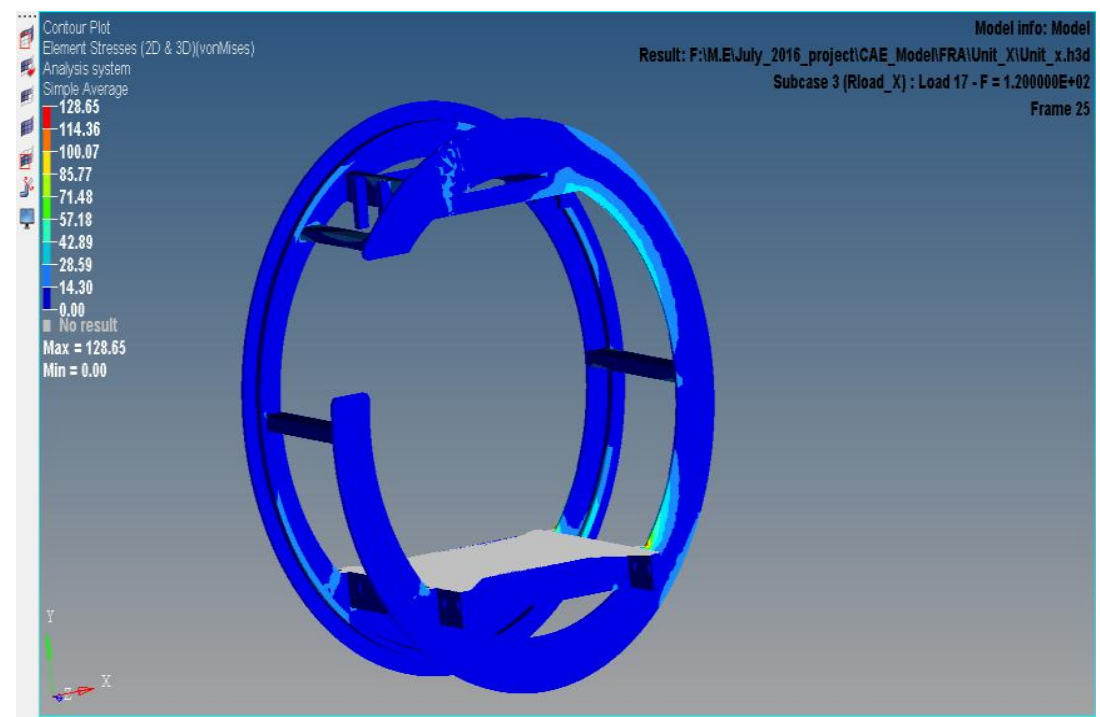

Fig 6.2.3 Stress plot for $120 \mathrm{~Hz}$ frequency
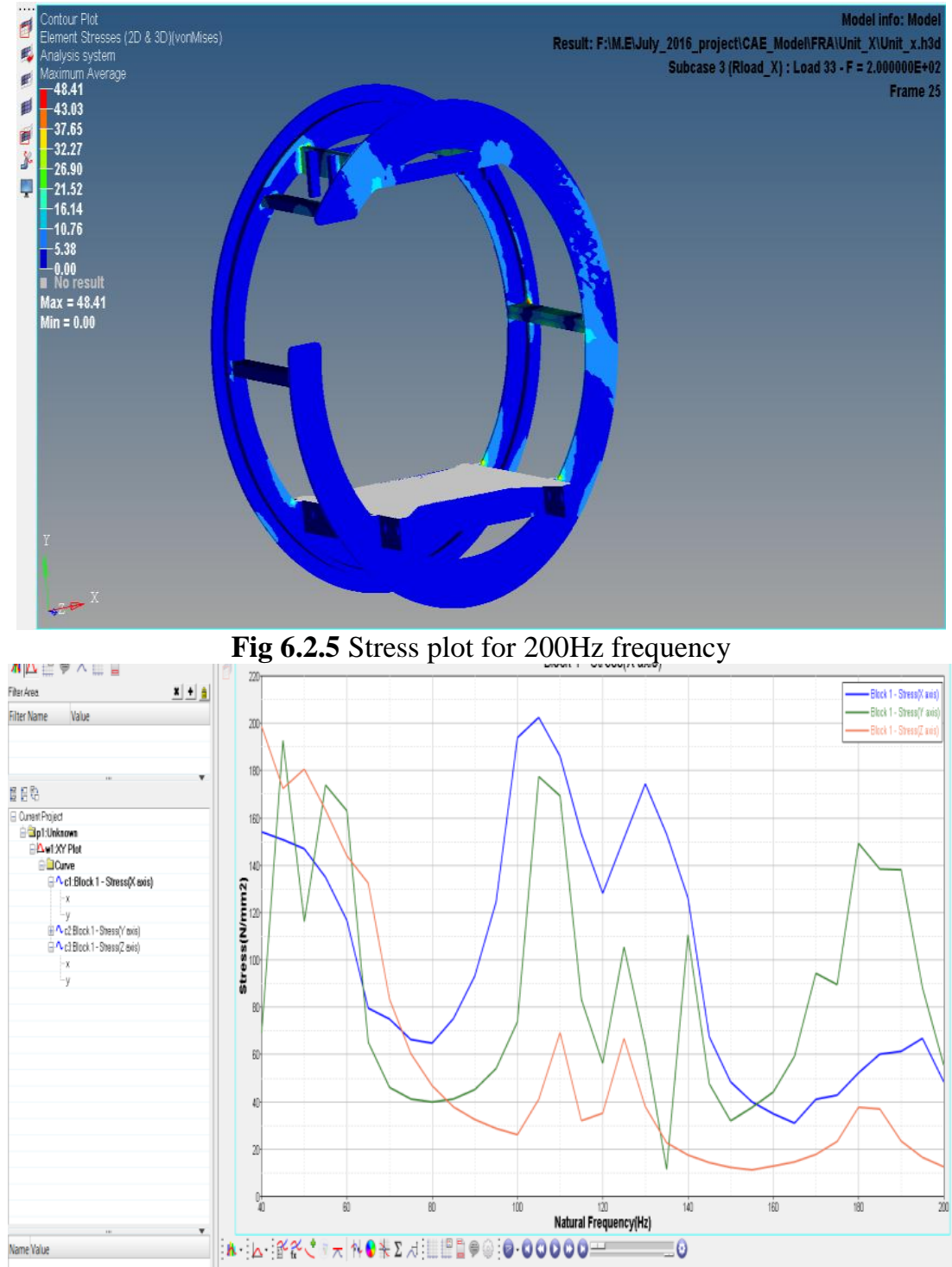

Graph 6.1 Natural frequency Vs Stress 


\subsection{Result for frequency Vs Amplitude}

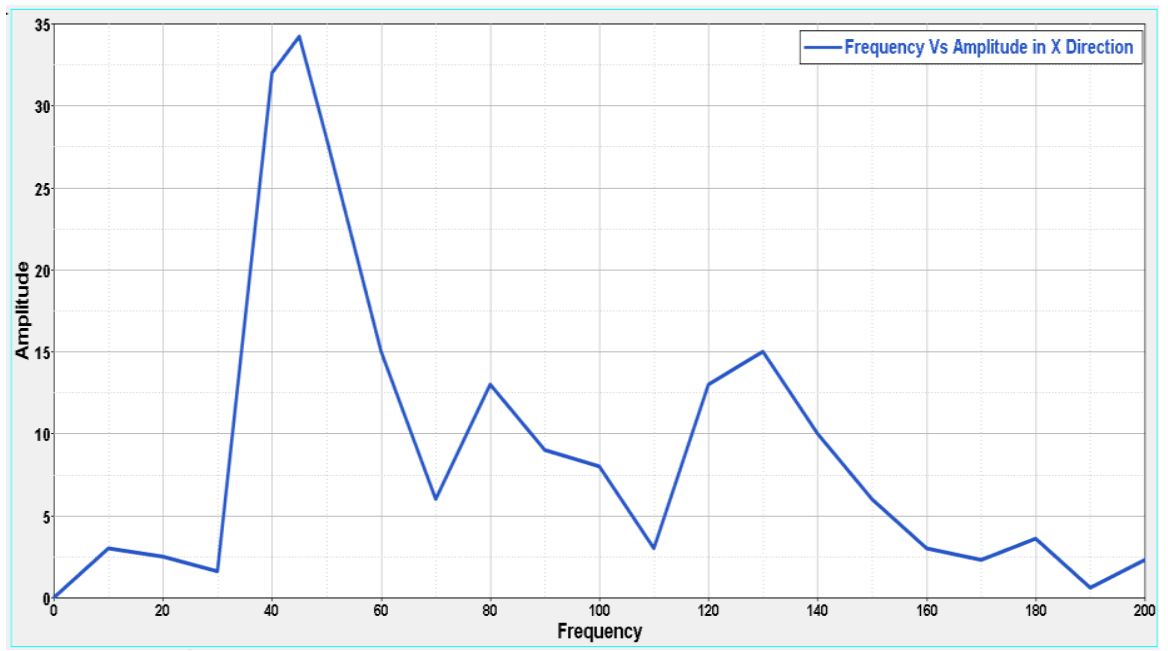

Graph 6.2: Frequency Vs Amplitude in X-direction

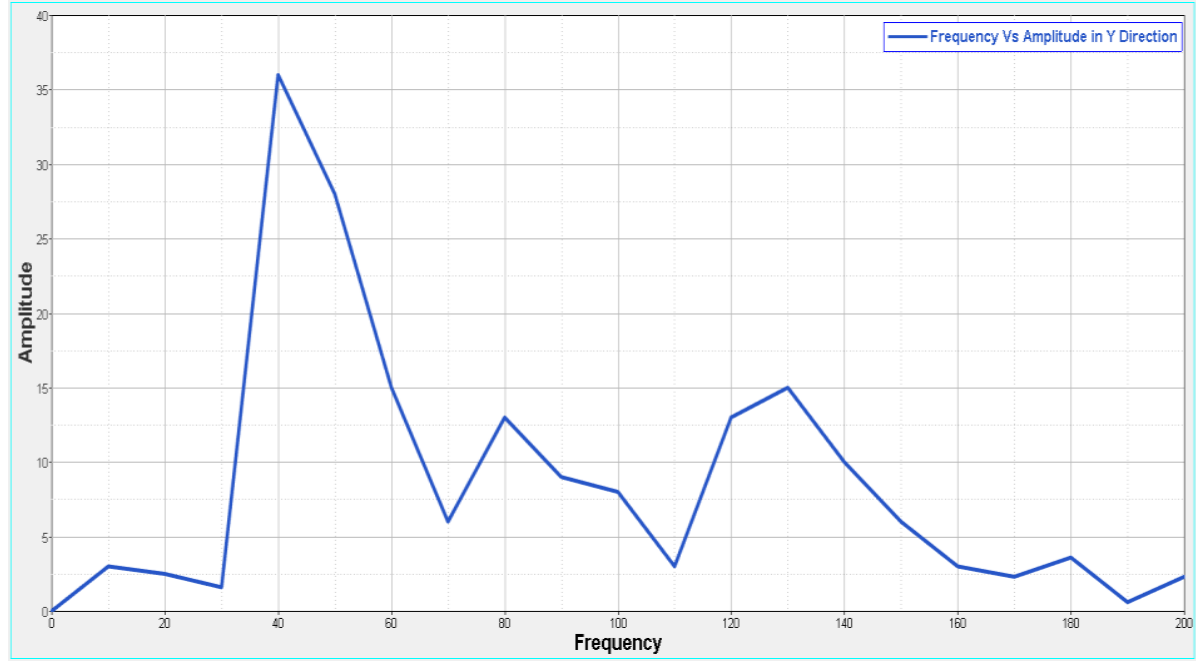

Graph 6.3: Frequency Vs Amplitude in Y-direction

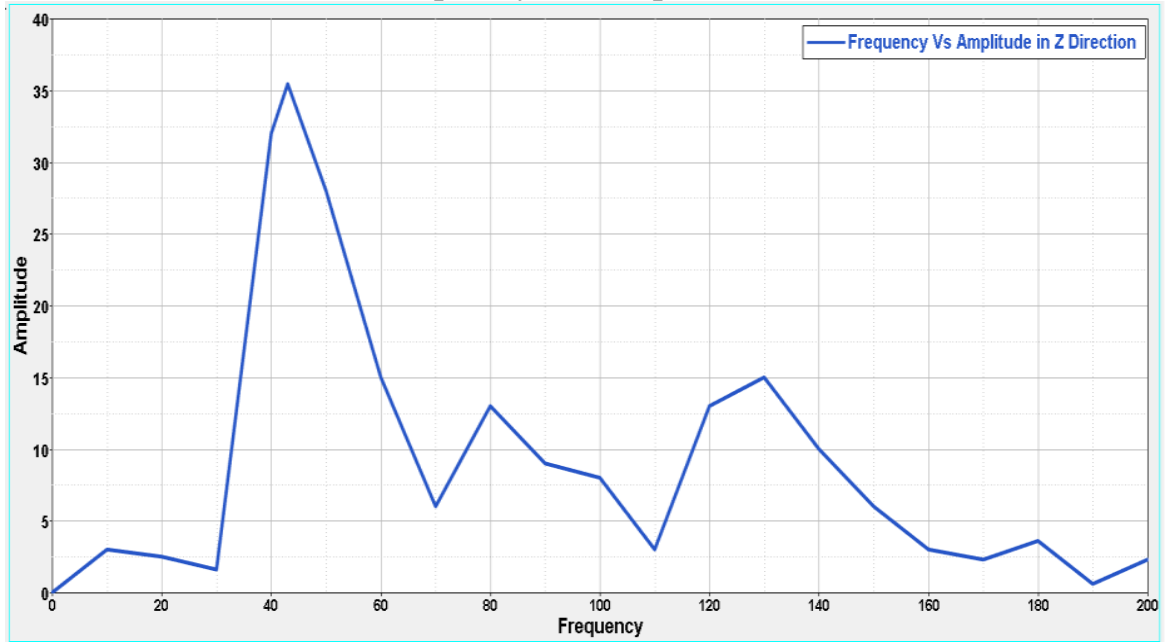

Graph 6.4: Frequency Vs Amplitude in Z-direction 


\section{Experimental Measurements}

The main purpose of the strain gauge measurements was to obtain stress history data for known positions on the Tippler structure. This data was used to verify the accuracy of the FEA model of the Tippler structure that was constructed and as input data for the calculation of the fatigue life for the original and modified Tippler structure. A detail analysis was however done on the data obtained to identify any additional factors that could have an influence on the fatigue life of the structure but cannot be easily simulated by means of a FEA. Some of these factors include internal residual stresses, forces generated by misalignment between structural components or friction in connections and pins. Note that the stress results obtained from the strain gauges do not include mean stresses in the structure caused by gravitational acceleration as the strain gauges were applied and their outputs set to zero while the structure was subjected to gravitational acceleration.

\subsection{Description of the strain gauge equipment used}

The rotation of the Tippler structure during operation makes difficult to do strain gauge measurements with conventional wiring methods, as the wires tend to accuracy. Used instruments in workshop for primary working load test of welded drum body, Strain gauge tester and indicator we used with the specification:

- Highly accurate measurement strain gauge and other sensor's resistances.

- Precise measurements of resistance deviations between gauges.

- Precise measurements of resistance to ground of strain gauge installations, range up to $20 \mathrm{G} \Omega$; test voltage $20 \mathrm{~V}$.

- Determination of strain gauge installation offsets

- Function test of strain gauge installations with built-in signal conditioner/amplifier.

\subsection{Strain gauge positions}

The decision as to where to apply the strain gauges had to be made before any finite element results were available. It was therefore decided to apply the strain gauges at positions on the structure where there are no stress concentrations that could complicate check calculations. The strain gauge measurements were not aimed at determining the stress at a specific position, but to determine the general stress in a structural member when the Tippler is rotated to a certain position. As mentioned before, the main focus of this investigation is on the in go cage. Most of the strain gauges were therefore applied to this cage with some applied to the in go side forces on this cage. The measured stresses were to be compared to the stress values for the corresponding locations and Tippler positions, obtained from the finite element results. The following positions were selected:

On in go outgo end ring

On top of the cross beam

On bottom plate of platform structure

\subsection{Strain gauge installation and set up procedure}

For the application, a half-bridge strain gauge arrangement was used. This arrangement compensates for temperature changes that may influence the strain gauge readings during operation. Note that local bending on the strain-gauged plates was ruled out because of the section size of the structure where the strain gauges were applied. The properties of the strain gauges used are as follow.

Table 7.3 properties of the strain gauges

\begin{tabular}{|l|l|}
\hline Gauge type and arrangement & KFG $90^{\circ}$ Rosette - applied in a half bridge arrangement \\
\hline Gauge type & Steel \\
\hline Gauge resistance & $120 \Omega$ with $5 \mathrm{~mm}$ grid length \\
\hline Gauge factor & 2.12 \\
\hline
\end{tabular}




\subsection{Experimental Result}

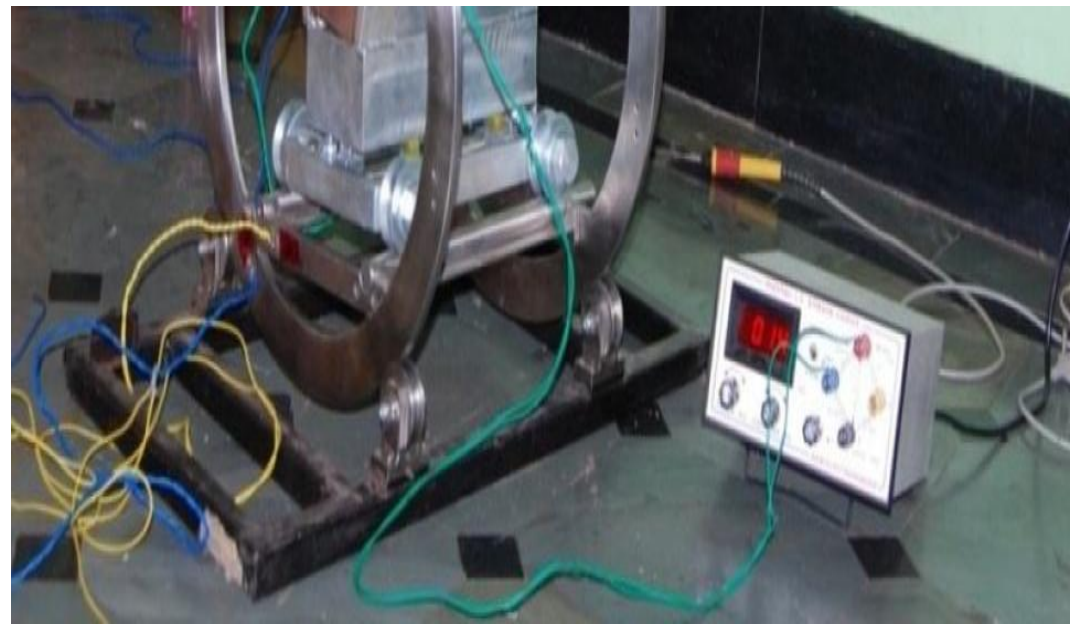

Fig: 7.4.1 45 degree angle

Table: 7.4.1 Comparison of Result

\begin{tabular}{|l|l|l|l|}
\hline \multirow{2}{*}{ Angle(Degree) } & Stress $(\mathrm{N} / \mathrm{mm} 2)$ & Strain & \multicolumn{2}{|l|}{} \\
\cline { 2 - 4 } & Numerical Method & Numerical Method & Experimental Method \\
\hline 45 & 3.24 & $1.34 \mathrm{e}-4$ & $1.4 \mathrm{e}-4$ \\
\hline 90 & 2.91 & $1.68 \mathrm{e}-5$ & $2.0 \mathrm{e}-5$ \\
\hline 135 & 3.24 & $1.34 \mathrm{e}-4$ & - \\
\hline 180 & 2.91 & $1.68 \mathrm{e}-5$ & - \\
\hline
\end{tabular}

7.5 Frequency response analysis test

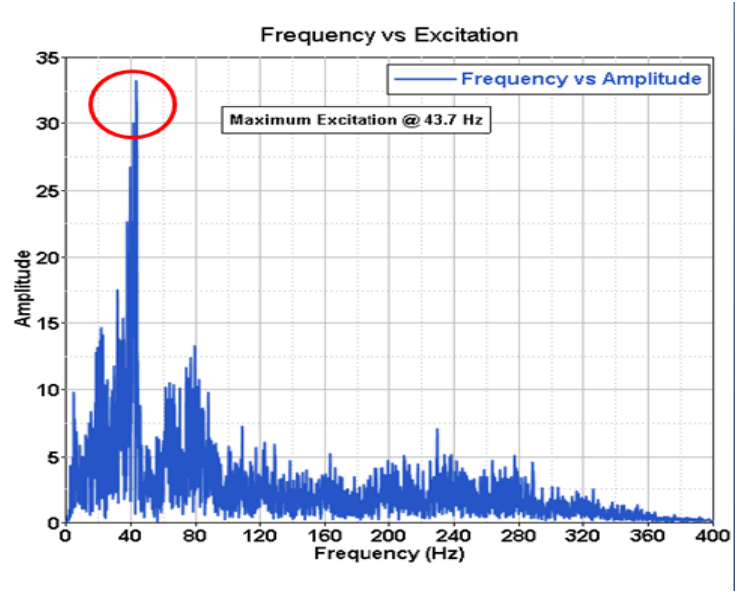

Graph 7.1: Frequency Vs Amplitude in X Direction 


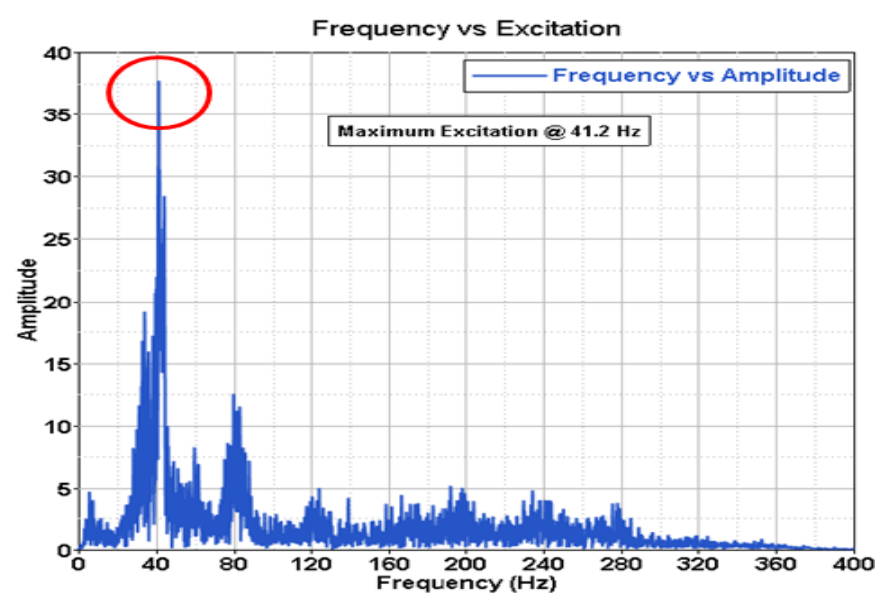

Graph 7.2: Frequency Vs Amplitude in Y Direction

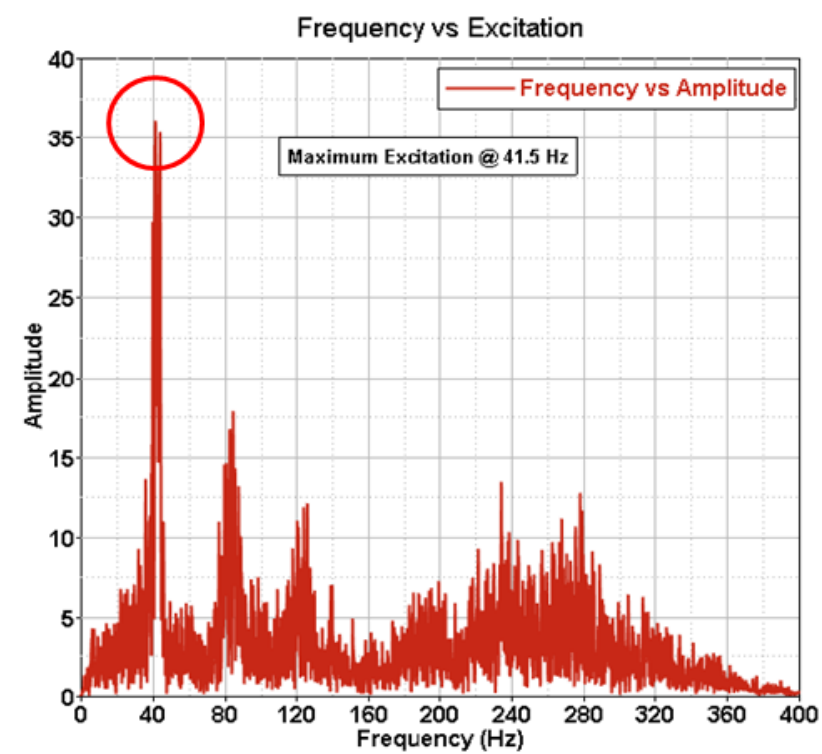

Graph 7.4: Frequency Vs Amplitude in Z Direction

Table: 7.3 Comparison of Result (Dynamic load)

\begin{tabular}{|l|l|l|l|l|}
\hline \multirow{2}{*}{ Direction } & \multicolumn{2}{|l|}{ Numerical method } & \multicolumn{2}{l|}{ Experimental method } \\
\cline { 2 - 5 } & Amplitude (Max.) & Frequency(Hz) & Amplitude (Max.) & Frequency(Hz) \\
\hline X-axis & 34.04 & 44.74 & 33.46 & 43.7 \\
\hline Y-axis & 35.82 & 40.03 & 37.84 & 41.2 \\
\hline Z-axis & 36.26 & 43.32 & 36.09 & 41.5 \\
\hline
\end{tabular}




\section{Process Optimization}

Here round drum rotation allowing making multiple operations in one cycle instead doing multistage operation. We convert processes on multi station to multi angle as our product gives rotational stoppages at multi angle positions to perform facing operations of drilling, tapping burr, washing and cleaning with air blow drying also. Now previously the process was manual as shown. Total 22 minutes takes in process for each component.

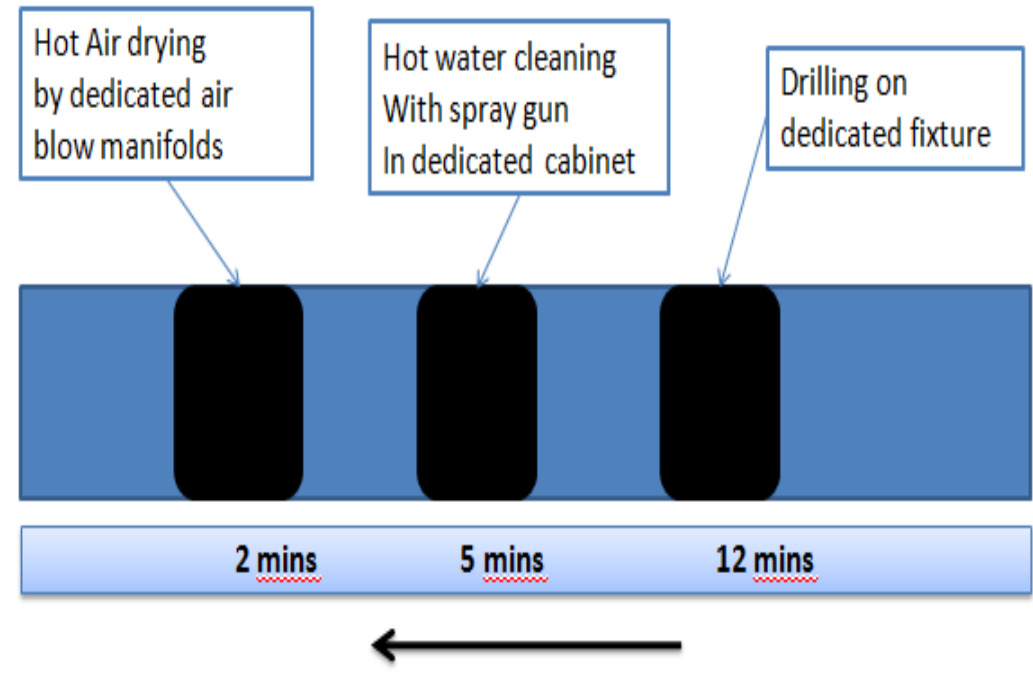

Total 19 minutes manual cycle time of operations only

For fixing and arrangement of parameters approx 2-3 minutes

Fig: 8.1 Fixture Indexing Layouts

In one stage one machine operation all these processes are in one context, Cycle time is 9 minutes i.e. drilling 5 minutes simultaneously manifolds acting to clean and wash holes to make deburring and removes oil and coolant. 4 minutes given to air blow and drying component which will be ready to assembled. Optimised process is $60 \%$ more efficient .Saving total 13 minutes in each cycle. Total components passing through one shift in a day 19 to 20 in 7 hours (420 minutes) working shift. Now it will be 46 with using this rotary drum automation.

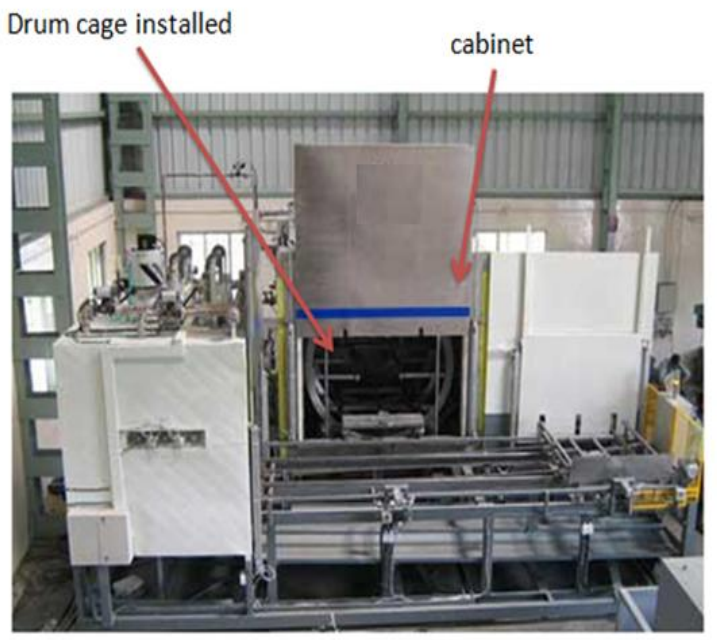

Fig: 8.2 Trail of Cage Fixtures in Plant 


\section{Conclusion}

Total strain (45 Degree) 0.134 found in drum as per FEA \& 0.14 found in physical validation, Stress level also $3.24 \mathrm{~N} / \mathrm{mm} 2$ found against $300 \mathrm{~kg}$ Load. Which shows it will work without failure as per structural behavior of material.

Total strain (90 Degree) 0.124 found in drum as per FEA \& 0.02 found in physical validation, Stress level also $2.91 \mathrm{~N} / \mathrm{mm} 2$ found against $300 \mathrm{~kg}$ Load. Which shows it will work without failure as per structural behavior of material.

The frequency of first Mode is found $45.12 \mathrm{~Hz}$. Which is greater than minimum criteria $(44 \mathrm{~Hz})$ According to regulation of JIS, it means no failure will be found due to resonance.

In frequency response analysis, stresses are always found less than $210 \mathrm{~N} / \mathrm{mm} 2$ (yield stress of steel) for every frequency band and all three Direction $(\mathrm{X}, \mathrm{Y}$ and $\mathrm{Z})$. Which is come from external excitation. This shows no failure.

The model of component is made using the appropriate co-ordinate system on the computer. The required boundary conditions are given $\&$ a variety of data can be generated. In CAE analysis, nowadays dynamic behavior is becoming the most popular technique as it does not require physical prototype for testing purpose but it takes large time initially to validate the computer model.

Product Manufacturing Cycle Time reduced. Optimized process: $60 \%$ more efficient. Saving total 13 minutes in each cycle. Total components passing through one shift in a day 19 to 20 in 7 hours (420 minutes) working shift. Now it will be 46 with using this rotary drum automation.

It has been concluded that round structured drum type horizontal fixture is possible to make indexing for heavy components in SPM.

\section{Future Scope}

The design of different components has become possible with help of Finite Element Analysis without taking the actual test over the components. one can predict the failure possibility of the components. The static, fluidic, heat exchange etc problem can solve by FEA. Design by analysis is one of the best methods with which very complicate, huge, or any other particular shape can design.

Here for this project we use steel material and saw the stress and strain in static condition as well as dynamic condition, so from the final result we conclude following point which can improve the feasibility of fixture.

Design of fixture is so heavy for existing loading condition because stress is found very less from yield property of material, so optimization is required. for optimization, one analysis is required which is called optimization analysis. Due to this cost of fixture will reduce.

After Optimization, Random vibration analysis is required in dynamic analysis. 


\section{References}

[1]. Taufif Bin Zakaria, "Dedicated fixture design for polishing of silicon", University of Malaysia Pahang, pp 138-193, November 2008

[2]. Thomapson and Ghadhi (1986), "Design of Modular fixture for Flexible manufacturing systems", Journal of Manufacturing system, 5(4), pp 243-254, 1986

[3]. Gandhi M.V. and B. S. Thompson, "Automated design of Modular fixture for Flexible manufacturing systems", Journal of Manufacturing system, 5(4), pp 243-254, 1986.

[4]. Nee \& Kumar "Assembly with automatically reconfigurable fixture", IEEE journal of robotics and Automation, 1985-1991.

[5]. Shoji Naguchi, Satoshi Nakayama, et.al., "Static stress analysis of link plate of roller chain using finite element method and some design proposal for weight saving”, Journal of advance mechanical design, system and Manufacturing, 3(2), pp.159-170, 2009.

[6]. Asada, H. and A.B. By. Kinematic Analysis of Work part Fixturing for Flexible Assembly with Automatically Reconfigurable Fixtures. IEEE Journal of Robotics and Automation, 1(2), pp. 86-94. 2000

[7]. Wang, M., .Tolerance analysis for fixture layout designs. Assembly Automation, Vol. 22, pp. 153-162, 2002.

[8]. Wu, Y., Rong, Y., and Chu, T.C., .Automated generation of dedicated fixture designs..International Journal of Computer Applications in Technology, Vol. 10(3/4), pp. 213-235, 1997.

[9]. Wu, Y., Rong, Y., Ma, W., and LeClair, S.R., .Automated modular fixture Planning Geometric analysis., Robotics and ComputerIntegrated Manufacturing, Vol. 14, pp. 1-15, 1998.

[10]. Krishna Kumar , K. and Melkote , S.N., .Machining fixture layout optimization Using the genetic algorithm. Intl Journal of Machine Tools and Manufacture, Vol. 40, pp. 579- 598, 2000.

[11]. Roy, U. and Liao, J., .Fixturing analysis for stability consideration in an automated fixture design system., Journal of Manufacturing Science and Engineering, Vol. 124, pp. 98-104, November 2002.

[12]. Liu, J.J-X. and Strong, D.R., .Machining fixture verification for nonlinearFixture system., International Journal of Advanced Manufacturing Technology, Vol. 21, pp. 426-437, 2003.

[13]. Indian stream research journal val II , Issue : VIII Sep-2012 ISSN 2230- 78 Design And Analysis Of Dedicated Fixture For Multistage Special Purpose Machine By M. Y. Dakhole 1, P.G. Mehar 2and V.N. Mujbaile

[14]. Diana M. Pelinescu, Micheal Yu Wang, "Multi-objective optional fixture layout design" Robotics and computer aided Manufacturing, 18 (2002), pp 365-372.

[15]. Andrew Yeh Chris Nee, Zien Jun Tao, A. Senthil kumar "An advance treatise on fixture design and planning", Series on manufacturing technology, Vol. I.

[16]. Application note011 Basic of structural vibration testing \& analysis.

[17]. JIS (Japanese Industrial Standard) -D1601-1995 Regulation 4933608-0525642-366

[18]. The Relationship between Finite Element Analysis and Modal Analysis by Neville F. Rieger, Stress Technology Incorporated, Rochester, New York

[19]. International Journal of Mechanical Engineering and Research. ISSN 2249-0019, Volume 3, Number 6 (2013), pp. 603-608 Finite Element Modeling and Frequency Response Analysis of Front Cradle.

[20]. To Study the Dynamic Behavior of Engine Assembly by Using Altair Optistruct HTC-2012

\section{Hand Books}

[21]. Structural analysis on tippler structure, University of Pretoria by Petrus Johannes adriaans vanzyl.

[22]. Supererg Suksai, "Mechanical Design handbook".

[23]. Power transmission Design", 1997, Handbook issue (Serial)[Paperbook], Vol.39, Page A115 - A120.

[24]. Chain drive selection, “U. S. Tsubaki RS roller chain”, Page A22 - A24. 